\title{
Planning an Authority Control Project at a Medium-sized University Library
}

\section{Sha Li Zhang}

Authority control is a vital part of providing students and faculty with adequate access to collections in university libraries. Although many large research libraries routinely maintain authority control, small and medium-sized university libraries find it challenging to meet rising user expectations and provide adequate access in an online environment through appropriate authority work. The smaller libraries have to provide persuasive data to demonstrate to their library administrations that tight staffing situations make it difficult to perform in-house maintenance on authority work and keep up with the dynamic and constant changes of new headings for bibliographic records. This article offers a planning process on an authority control project at a medium-sized university library.

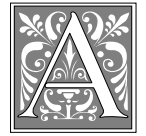

uthority control is a method that libraries must use to maintain consistency in their catalogs. As Robin K. Wendler stated: "Provision of consistent headings, together with a reference structure, allows searchers to isolate the particular author they are interested in and ensures that they find all available works by that author." ${ }^{\prime 1}$ Henriette D. Avram wrote that authority control consists of the following elements:

- distinguishing names: intellectual formulation of the correct form of name following precedent and /or standard rules;

- showing relationships: intellectual formulation of related names (variant forms, earlier or later names, parent bodies, etc.);
- documenting decisions: documentation of this information via creation of an authority record (thereby assisting subsequent users of the same heading in determining relationship and identifying headings on bibliographic records). ${ }^{2}$

In an online cataloging environment, authority control plays a more important role than ever before in enhancing user access to university library collections. Through adequate authority work, consistent headings with a cross-reference structure enable users to locate needed library materials effectively in online catalogs.

\section{Background}

Avram pointed out that authority control is required as much as ever in online

Sha Li Zhang is an Associate Professor and Head of the Technical Services Division in the Wichita State University Libraries; e-mail: shali.zhang@wichita.edu. The author wishes to thank the Office of Research Administration at Wichita State University, which granted a University Research/Creativity Projects Award to this project in December 1999. The author also wants to express sincere thanks to all cataloging staff at Wichita State University Libraries for participating in this project. 
catalogs. ${ }^{3}$ Users and librarians rely on the intellectual work of catalogers to distinguish items, works and versions, and headings. Although users are greatly assisted by the collocation of materials, catalogers themselves, as well as acquisitions and interlibrary loans staff, benefit from authority control.

The growing importance of authority control in academic libraries is evidenced by the considerable amount of attention given the topic in library literature in the past decades. Larry Auld's 1982 review of eighty-year-old authority control literature from circa 1900 to 1984 included forty-six references and a list of seven additional bibliographic readings. The scope of his literature review was limited to publications in the United States and Canada. ${ }^{4}$ In the same year, in a seminar paper on the topic presented to the Graduate School of Library and Information Science at UCLA, Barbara Tillett included 411 works. Except for thirteen, all of the works in Tillett's citations were published after the 1960s. ${ }^{5}$ In Arlene G. Taylor's 1989 literature review concentrating on the philosophical aspects of authority control published in the 1980s, sixty-one works were cited, excluding those cited by Auld and Tillett. ${ }^{6}$ The author's recent search on the LibraryLit database, a subset of OCLC's FirstSearch, revealed more than 450 entries that contain the phrase "authority control" published in library literature from 1984 to the present. ${ }^{7}$

Maintaining adequate authority work in university libraries is costly and laborintensive. In large research libraries, the cost of maintaining authority control has been a part of routine expenditures on cataloging and database maintenance, although the levels of authority control vary from library to library. In 1979, authority control cost ARL libraries approximately $\$ 5$ million. ${ }^{8}$

Although maintaining authority control has been a routine activity in many large research libraries, being able to meet rising user expectations and provide adequate access in an online environment through appropriate authority work has been a challenge for small and mediumsized university libraries. In her 1992 article, Joan M. Bechtel stated that "in an undergraduate academic library the most persuasive and responsible argument for providing authority control is that retrieval and use of information are significantly enhanced. If the organization of materials is improved, that is, if the work of the catalog librarians is also enhanced by authority control, that is a bonus. Academic librarians, however, must not lose sight of the fact that their raison d'être is service to students and faculty, not their own comfort. ${ }^{9}$ Elaine Peterson and Bonnie Johnson estimated that it would cost $\$ 12,000$ annually at the Montana State University Library to keep the authority file current. With this amount of funding, three hundred new titles would be purchased. However, Peterson and Johnson were convinced that "if given the choice to buy 300 new titles which would be difficult to find or separated from other like materials in the catalog, or to bring all materials together into one place for the user by spending the money on authority updating, the choice is clear. Once in an automated library, no patron is likely to leave the online catalog screen and use such tools as the LCSH red books (Library of Congress Subject Headings), even if the catalog is known to be deficient. Authority maintenance is a must if patrons are to receive all information they need in one place."10

The cost and staffing vary in maintaining authority work, depending on the size of the library's bibliographic records and the level of authority work it wishes to perform. It proves overwhelmingly that, with tight staffing situations, purely in-house maintenance work on authority control is no longer able to keep up with the dynamic and constant changes of new headings for bibliographic records in small and medium-sized university libraries. As Kerrie Talmac pointed out, "Although local systems may be able to make some global changes, staffing cutbacks and the attrac- 
tiveness of external agency services have led an increase in the number of libraries looking beyond their own resources to obtain the required level of cataloging integrity." 11 At the University of Dayton Library, another medium-sized university library, Susan L. Tsui and Carol F. Hinders concluded that using a vendor service for authority control "contributes to a library's cataloging efficiency and helps improve the search capability and potential results for its users." 12

\section{WSU Library Cataloging Environment}

Wichita State University (WSU) is one of three research institutions in the state of Kansas. The university also assumes the role of serving the educational needs in the metropolitan area of Greater Wichita. The university community includes about 15,000 students and 1,700 faculty and staff members. WSU Libraries currently holds more than 1.2 million volumes of materials, with more than two million acquisitions budgeted for annually. Although the university offers ten doctoral programs and forty-five master's programs, most students who come to WSU enroll in a hundred and fifty undergraduate programs whose needs for research materials consist of both serial and monographic formats and both print and digital media.

WSU Libraries automated its cataloging system to NOTIS online catalog in 1985. Though the library's users had access to other libraries' online catalogs through union catalogs, they depended heavily on access provided by the library's online catalog, named LUIS (Library User Information Service), to the library collections. Each year, about 25,000 new titles are added to the library collections. As in the case of many small and medium-sized university libraries, the limited funding and tight cataloging staff prevented the library from fully implementing authority control at that time. Authority work remained in a very limited scope at the library. Authority records were created locally or exported from the OCLC Authority Files into the local catalog system only for music records, media records, and serial records. By November 1999, prior to the library's system migration there were about 65,000 authority records in its NOTIS cataloging system cumulated since 1985 . That was a very small fraction, comparing more than one million bibliographic records in the cataloging system. Furthermore, these authority records had not been updated since the dates they were created or exported into the local catalog. Therefore, the changes in new, revised, and obsolete headings were not reflected in the local authority record file.

The updated bibliographic records from the vendor were linked to more than 650,000 authority records in the new catalog system.

In 1998, the library started importing bibliographic records in batch loads from a book vendor for both firm orders and approval books. This procedure represents 85 percent of new bibliographic records imported into the local cataloging system on a monthly basis. The remaining bibliographic records came from OCLC's WorldCat. The bibliographic records that are batch-loaded from the book vendor include full MARC records created by the Library of Congress (LC), CIP records, upgraded CIP records, and provisional records created by the vendor's cataloging staff. These bibliographic records were entered into the library's local system as they were, and no authority reviews were performed at that point. About 25,000 bibliographic records for new titles have come from this source annually. The bibliographic records imported from OCLC's WorldCat were reviewed for valid headings on a one-by-one basis, including music, media, and serial records. The headings for records created by the Government Printing Office and exported from OCLC's WorldCat also are reviewed because the library has been cata- 
loging all incoming government document materials since 1994. The library has been receiving 62 percent of government documents issued by federal agencies since it became a federal deposit library in 1901. In the past decade, the library was able to maintain the stable acquisitions of monographs that supported large undergraduate programs at WSU. With gift materials, almost fifty thousand new titles were added to the library's online catalog in 1999 and 2000. Without adequate authority work, it was difficult to search and retrieve these valuable new collections.

In November 1999, prior to the library's system migration from NOTIS to Endeavor's Voyager online cataloging system, with one-time funding allocated by the library administration, the library contracted an authority control vendor to review and update all personal name, corporate name, series, conference name, uniform title, subject, and name/title headings for nearly one million bibliographic records. During the review process, obsolete and incorrect headings were replaced with valid and correct ones. The updated bibliographic records from the vendor were linked to more than 650,000 authority records in the new catalog system. This project enabled the library's new cataloging system to be cleaner and more consistent than before. Students and faculty were pleased with the outcome brought forth by the project when they started using the new cataloging system in January 2000.

\section{Planning the Project}

When the library's new cataloging system was in full operation in January 2000, the cataloging staff began using an authority validation tool of the cataloging system to review newly imported bibliographic records against the existing authority records in the database in the hope that all bibliographic records in the catalog would be kept up with heading changes. It was assumed that the headings of newly added titles were reviewed and updated upon cataloging with the validation tool. If the headings for a bibliographic record were invalid according to this validation tool, the cataloging staff would search the OCLC Authority File and export appropriate authority records into the local online system to validate the headings of the bibliographic records. When an OCLC search failed to locate an appropriate authority record, local authority records were created only for music, media, and serial records. No local authority records were created for monographic titles that represented a large portion of newly acquired materials.

At the same time, the cataloging staff became more concerned with keeping up with the existing authority records in the library's authority file. The LC issues 7,600 name authority records and 400 subject authority records every week. ${ }^{13}$ Though in many cases these headings may not affect the library's bibliographic records because of the collection levels of the library materials, there is no automatic method to identify a subset of these new authority records that do relate to headings in the library's catalog. One cataloging staff member spent an entire week checking a weekly list of new headings issued by the LC against the authority records in the library's local system. When an invalid heading was identified, the cataloging staff member would export an appropriate authority record from the OCLC Authority File and globally update all the invalid headings of bibliographic records in the local system. It was a very time-consuming process. Without ongoing authority work, library users would have a difficult time locating new titles. Therefore, the ongoing authority maintenance was brought to the discussion in the library's Technical Services Division. This means that additional annual funding has to be allocated to have a vendor provide the service, as well as to pay for in-house staff time to maintain adequate authority work.

During the discussion, the library administration supported this ongoing commitment. The Technical Services Di- 
vision would have to ensure the procedures that would merit the investment. The cataloging staff also looked into the following initiatives that would support the ongoing project:

1. The presence of technology: The library migrated to a new online cataloging system in November 1999 that was client-server based. This new system offers an authority validation tool, in addition to other modules such as acquisitions, cataloging, circulation, and OPAC. Table 1 displays the tool.

The authority validation tool informs the cataloging staff about invalid headings, first-time-use headings that need to be verified, and obsolete headings that need to be updated when new titles are cataloged. This new feature has substantially reduced the amount of time the cataloging staff has to spend manually on authority control functions. The new online cataloging system offers an excellent opportunity to incorporate authority control into the library's routine flow of cataloging work.

2. The presence of the large number of authority records: When the library contracted an authority control vendor to review and update headings for all bibliographic records in November 1999, the vendor also provided the library with 650,000 authority records. This procedure brought the library's online cataloging to the most updated level. It was a benchmark for the library's cataloging system. The cataloging staff in Technical Services Division wanted to grasp this excellent opportunity to maintain ongoing authority control.

3. Redesigning staff structure: In September 1999, the Technical Services Division redivided the existing cataloging workload, which comprised materials cataloging for commercially purchased materials, for incoming government documents, and for music and media materials. After redesigning the staff structure, three major cataloging tracks were created: Monographs Cataloging, Serials Cataloging, and Music and Media Cataloging. Three catalog librarians were as- 
signed to each cataloging unit as resource persons. They provide procedural guidelines, make recommendations, and assist the cataloging staff in authority work.

4. Application for the NACO Music Project (NMP): In 2000, an application for the NMP submitted by the Music and Media Cataloger was accepted and approved. Through this funnel, the cataloger started training through an independent and experienced NMP participant. The authority records for music materials created by this cataloger were then reviewed by the trainer. Subsequently, the revised versions of these records are contributed to the National Authority File. This catalog librarian also serves as a resource person on the authority control project.

\section{Outcomes of the Project}

During the planning process, three types of records were examined: the number of monthly exported authority records, the sample of unauthorized headings, and the number of monthly batch-loaded bibliographic records from a book vendor.

\section{Number of Monthly Exported Authority Records}

In March 2000, when the cataloging staff became familiar with the new online cataloging system and when the cataloging work flow also became more stable after the system migration, the cataloging staff was asked to keep as accurate a daily record as possible of the number of authority records that were searched from the OCLC Authority File and the number of authority of records that were actually found and exported into the library's local cataloging system. Upon cataloging each new title, the cataloging staff reviewed each bibliographic record for such headings as name, title, subject, name/title, uniform titles, and series by using the authority validation tool of the cataloging system. If the heading was invalid, the cataloging staff would go to the OCLC Authority File to search and export corresponding authority records for the headings. If no authority record was available, a local authority record was created for a serial record, a music record, and a media record. No local authority record was created for monographic copy cataloging materials. The recordkeeping part was very time-consuming. The cataloging staff felt much relieved when it was over at the end of the month.

According to the daily record-keeping, the name heading consists of a large part of authority records that the cataloging staff exported from the OCLC Authority File during the month. In this category, 845 authority records were exported into the library's local online cataloging system. Nineteen local authority records for name headings were created. The next large category is the subject heading. The cataloging staff exported ninety-three subject authority records. For series records, seventy-six authority records were exported to the local cataloging system. Four local series authority records were created. The category of name/title headings was a relatively small group. Only twenty-eight authority records were exported to the local database. Nine name/title authority records were created. In summary, in March 2000, the cataloging staff exported a total of 1,049 au-

\begin{tabular}{|lcccccc|}
\hline \multicolumn{5}{c|}{ TABLE 2 } \\
Summary of the Authority Record Activity in March 2000 \\
\hline \hline $\begin{array}{c}\text { Sources of } \\
\text { Authority Records }\end{array}$ & $\begin{array}{c}\text { Name } \\
\text { Headings }\end{array}$ & $\begin{array}{c}\text { Subject } \\
\text { Headings }\end{array}$ & Series & $\begin{array}{c}\text { Name/ } \\
\text { Title Headings }\end{array}$ & $\begin{array}{c}\text { Title } \\
\text { Headings }\end{array}$ \\
\hline Exported from OCLC & 845 & 93 & 76 & 28 & 7 \\
Locally created & 19 & 0 & 4 & 9 & 7 \\
\hline Total & 864 & 93 & 80 & 37 & 14 \\
\hline
\end{tabular}


TABLE 3

Descriptive Summary of Authority Records in 2000 (12 months)

\begin{tabular}{lccccc}
\hline \hline & Min. & Max. & Sum & Mean & Std. Deviation \\
\hline $\begin{array}{l}\text { Authority Records } \\
\text { Valid N }=12\end{array}$ & 320 & 1,049 & 7,721 & 643 & 216 \\
\hline
\end{tabular}

thority records from the OCLC Authority File to the local online cataloging system. The total number of locally created authority records was thirty-nine. Table 2 summarizes activity.

In table 3 , the number of authority records $(1,049)$ that the cataloging staff exported from the OCLC Authority File and locally created in March 2000 was much higher than the mean (643) in other months in 2000. The following factors contributed to this phenomenon:

- Because twelve cataloging staff members in the Cataloging Department kept a daily record on what they did on authority records, their record-keeping was collected every day in March 2000. That function served as a reminder for the cataloging staff, who kept the authority records activity in more accurate fashion in March 2000 than in other months. Although the cataloging staff kept activity records at other times, those numbers were collected on a monthly basis. Often there was a tendency to forget the record-keeping. Therefore, the number of authority records reported by the cataloging staff during other months was less than the number they actually worked.

- Three staff members from the Acquisitions Department and the Serials Unit of the Cataloging Department also participated in some levels of monographic copy cataloging activity when monographic backlogs went up in the Technical Services Division. Because of the complex nature of the authority control procedure, these staff members were not asked to review authority headings upon cataloging during the year except in March. Therefore, a certain percentage of headings of new monographic records were not reviewed during the cataloging process in other months.
The estimated staff time for reviewing and exporting the appropriate authority records is two minutes per record at the University of Dayton Library. ${ }^{14}$ At WSU Libraries, the cataloging staff reported the similar pattern of performing this function at between 1.8 and 2.3 minutes per record, or thirty-six hours per month for 1,100 records.

\section{Sample of Unauthorized Headings}

The number of unauthorized headings generated through the local cataloging reports was examined to determine whether the in-house authority maintenance was capable of keeping up with the newly issued authority headings by the LC. On a weekly basis, the system analyst who maintains the cataloging server at the WSU Computing Center runs several system reports for various headings. Table 4 displays samples of the number of incoming new bibliographic records whose headings were invalid; that is, there were no corresponding valid headings in the local authority file. Based on the reports, the cataloging staff had to export valid headings from the OCLC Authority File to validate all headings in the reports. Because of the large number of headings generated on a weekly basis, only a few weekly samples were selected here to show the significance.

As is indicated in table 4, according to the authority reports generated by the online system, a large number of unauthorized headings was detected, including unauthorized name headings, subject headings, name/title headings, and title headings. Because the system does not differentiate the genuine invalid headings from the valid headings that require some degree of editing/revising, 


\begin{tabular}{|lcccccc|}
\hline \multicolumn{7}{c|}{ TABLE 4 } \\
\multicolumn{7}{c|}{ Sample of Weekly System-generated Unauthorized Headings in 2000 } \\
\hline \hline & Week of & Week of & Week of & Week of & Week of \\
& Feb. & Mar. & Apr. & May & June \\
& $\mathbf{4 - 1 0}$ & $\mathbf{1 7 - 2 3}$ & $\mathbf{1 4 - 2 0}$ & $\mathbf{5 - 1 1}$ & $\mathbf{2 - 8}$ \\
\hline Unauthorized name headings & 409 & 689 & 421 & 266 & 248 \\
Unauthorized subject headings & 421 & 854 & 375 & 367 & 347 \\
Unauthorized name/title headings & 725 & 751 & 529 & 456 & 306 \\
Unauthorized title headings & 21 & 48 & 22 & 17 & 23 \\
\hline
\end{tabular}

it is very time-consuming for an in-house authority maintenance because the cataloging staff has to manually review each heading to decide when to export a valid authority record. Again, because the system does not differentiate main subject headings from subdivision headings, there was no other way to obtain the exact number of unauthorized main subject headings. If the number of unauthorized headings listed in table 4 was timed by four weeks, one could easily figure out the amount of staff time needed just to catch up with new headings detected by the local system each month.

\section{Number of Batch-loaded Bibliographic Records from a Book Vendor}

Finally, the number of newly imported bibliographic records from the book vendor was examined. In 2000, the total number of batch-loaded bibliographic records from the book vendor to the local cataloging system was 25,336 , an average of 2,111 per month. The bibliographic records from the vendor included both firm orders and approval books. As mentioned earlier, these bibliographic records were batch-loaded into the local cataloging system without being reviewed for their authorized headings. Table 5 lists the number of monthly batch-loaded bibliographic records.

The original intention of batch-loading bibliographic records from the book vendor was to speed up the acquisitions and cataloging process for newly purchased monographic titles. That is, if an imported bibliographic record was complete enough, the acquisitions staff would attach purchase orders and invoices to it. After that, the cataloging staff would simply add local holding and item records to the bibliographic record and would not go to OCLC's WorldCat to search and export the same bibliographic record into the local system. Based on the library's current cataloging procedures, the cataloging staff still needs to go to the OCLC Authority File to search and export the appropriate authority records upon cataloging the new titles. This procedure substantially slows down the entire cataloging process.

\section{Additional Findings of the Project}

After examining the current authority control work flow, analyzing heading reports generated by the cataloging system, and reviewing the batch-loaded cataloging records, it became very clear that:

1. Additional staff time is needed to incorporate authority control into routine cataloging work flow, including time spent searching, reviewing, and exporting the appropriate authority records; checking the weekly list of new headings issued by the LC against the headings in the local system; and updating the existing authority records. Although the online cataloging system provides a function of global heading changes (see table 6), it still requires manual reviews and updates on each heading that is related to bibliographic records in the library's catalog. The cataloging staff needs to manually click on the "Process" button, and the system analyst needs to run a global update program in the system server to complete each update. 
2. The costs for in-house authority maintenance include the fees of exporting authority records from the OCLC Authority File, the staff time spent on maintaining new headings, and the staff time spent on updating the existing headings. In their analysis on staffing cost, Susan L. Tsui and Carol F. Hinders concluded that the cost for the total manual exporting authority records from OCLC, for staff time of reviewing and loading appropriate authority records, and for manual review of the existing authority records is more than having a vendor service that "provides automatic machine correction of bibliographic records and supplies authority records with their revised forms, leaving the library only the complicated database maintenance of its manual review and correction."15

3. The level of commitment to the authority control procedure in the library's Technical Services Division includes:

- Head of Technical Services Division: Planning and coordinating work flow and assignments for incorporating authority control into routine cataloging work flow;

- Cataloging librarians: Serving as resource persons for the authority control process;

- Paraprofessional cataloging staff (library assistant III): Creating local authority records for original cataloging materials and for series if these records are not available in the OCLC Authority File;

- Paraprofessional cataloging staff (library assistants I and II): Searching, reviewing, and exporting authority records from the OCLC Authority File into the local system.

4. Substantial training for the cataloging staff at library assistants I and II levels is needed because of the complex nature of the process.

5. The speed of cataloging new monographic titles is slowed down. The cataloging staff has to review authority headings at the time of cataloging. These additional steps on authority work have slowed the pace of processing new materials. 


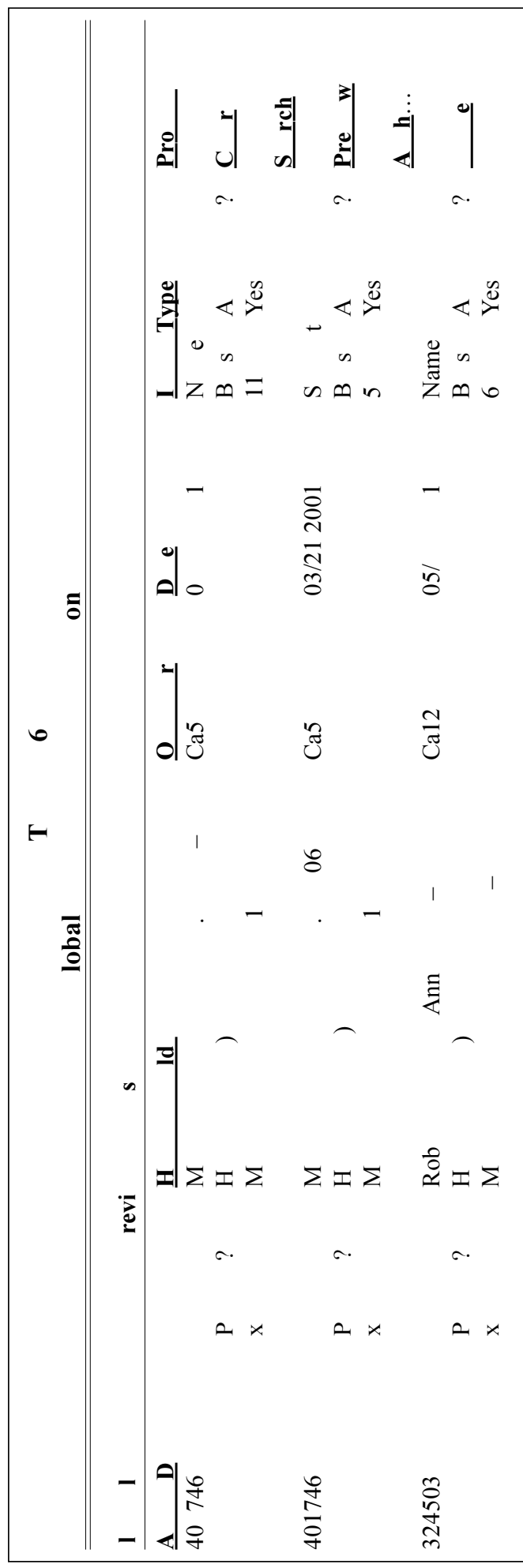

Recommendations and

\section{Conclusion}

Based on the cataloging data, the impact on cataloging work flow, and cost estimates, it was recommended to the library administration that in order to keep the local cataloging system consistent and current, two procedures must be in place (1) to validate headings for new bibliographic records exported from the book vendor and from OCLC's WorldCat on a regular basis, and (2) to update the existing authority in the local system whenever LC issues new headings that affect the local headings. There are 650,000 authority records in the library's cataloging system. Each week, the LC issues a long list of headings, including both new headings and replacements for old/obsolete headings. Because the cataloging staff has no way of knowing which existing heading in the local authority file needs to be replaced, the task of manually searching and comparing each heading issued weekly by LC will require a full-time cataloging staff member.

After a thorough review of the current cataloging work flow, a better understanding was gained that in-house authority work would take a large amount of staff time. It is almost impossible to keep the cataloging database current through the in-house maintenance. Ample library literature has provided convincing data that the cost of outsourcing this procedure is lower than the cost of in-house maintenance. Therefore, the Technical Services Division recommended selecting a vendor to perform the authority control procedures for the library. The library administration is taking the recommendations seriously. The funding for maintaining authority control is being included in the budget plans of the 2001/2002 fiscal year. 


\section{Notes}

1. Robin K. Wendler, "Automating Heading Correction in a Large File: Harvard's Experience," in The Future Is Now: Reconciling Change and Continuity in Authority Control (Columbus, Ohio: OCLC, 1995), 5-10.

2. Henriette D. Avram, "Authority Control and Its Place," Journal of Academic Librarianship 9 (Jan. 1984): 331-35.

3. Ibid., 333.

4. Larry Auld, "Authority Control: An Eighty-year Review," Library Resources \& Technical Services 26 (Oct./Dec., 1982): 319-30.

5. Barbara Tillett, "Automated Authority Control: A Survey of Literature," seminar paper (Los Angeles: Graduate School of Library and Information Science, Univ. of California, June 1982), with corrections and additions, Oct. 1982.

6. Arlene G. Taylor, "Research and Theoretical Considerations in Authority Control," in Authority Control in the Online Environment: Considerations and Practices, ed. Barbara B. Tillett (New York and London: Haworth, 1989), 29-56.

7. http://www.oclc.org/firstsearch/databases/ LibraryLit database, accessed in Mar. 2001.

8. Taylor, "Research and Theoretical Considerations in Authority Control," 33.

9. Joan M. Bechtel, "An Authority Control Alternative for Small Colleges," College \& Research Libraries 53 (Nov. 1992): 485-98.

10. Elaine Peterson and Bonnie Johnson, "Is Authority Updating Worth the Price?" Technicalities 10, no. 5 (May 1990): 1+.

11. Kerrie Talmac, "Authority Control," in Technical Services Today and Tomorrow, $2^{\text {nd }}$ ed. (Englewood, Colorado: Libraries Unlimited, 1998), 129-39.

12. Susan L. Tsui and Carol F. Hinders, "Cost-Effectiveness and Benefits of Outsourcing Authority Control," Cataloging \& Classification Quarterly 26, no.4 (1998): 43-61.

13. Library Technology, Inc., documents at http://www.LibraryTech.Com/index.html, accessed in Mar. 2001. 59.

14. Tsui and Hinders, "Cost-Effectiveness and Benefits of Outsourcing Authority Control,"

15. Ibid., 59. 